\title{
Retroperitoneal Giant Schwannoma: Difficulties in Diagnosis and Subsequent Surgical Management
}

\author{
MA RAHMAN ${ }^{\mathrm{a}}$, NU MAHMUD ${ }^{\mathrm{b}}$
}

\begin{abstract}
Summary:
Management and excision of left hypochondriac mass of a 55 year old lady have been presented in the paper. The ultrasound of whole abdomen showed two big lumps in the left hypochondriac and lumbar region which after excision turned out to be a retroperitoneal schwannoma. The mass was removed by sacrificing the left kidney. Though it is a highly specialized operation and should be performed in a
\end{abstract}

\section{Introduction:}

The term retroperitoneal tumour is usually confined to lesions arising from tissues-muscles, fat, fibrous tissue, lymph nodes, nerves (24\%) and developmental remnants (75\% mesodermal) of this compartment but excluding origin from retroperitoneal organs (pancreas, kidneys, ureters and adrenal glands) ${ }^{1}$. The incidence of primary retroperitoneal tumours is 0.3 to $03 \%^{2}$. Retroperitoneal swellings may be cystic or solid, benign or malignant ${ }^{1}$. Schwannoma are rare tumour arising from schwan cells of peripheral nerve sheath ${ }^{3}$. Women (54\%) are more affected than men $(46 \%)^{4}$. Most of the retroperitoneal schwannomas are benign ${ }^{4}$, locally aggressive and rarely metastasize $^{2}$. It rarely form cysts, cystic changes are noted in $63 \%$ of benign and $73 \%$ malignant schwannomas resulting from alterations in vascular wall ${ }^{3}$. The main symptoms are abdominal pain (85\% of all cases) and distention $^{1}$. It has no imaging characteristics and very difficult to diagnose preoperatively. Diagnosis is possible by means of immunohistochemistry stain for S-100 protein which distinguish schwannomas from spindle cell tumours $^{3}$. As the tumour is resistant to chemoradiotherapy ${ }^{2}$, surgical approach should focus on

a. Professor Md. Ataur Rahman, MS (Surgery), Professor of Surgery, Comilla Medical College Hospital

b. Dr. Nasir Uddin Mahmud, FCPS (Surgery), Assistant Professor of Surgery, Central Medical College Hospital, Comilla

Address of Correspondence: Professor Md. Ataur Rahman, MS (Surgery), Professor of Surgery, Comilla Medical College Hospital. Received: 05 February, 2011

Accepted: 13 March 2012 specialized center, sometimes general surgeons are unable to avoid the operation due to low economic condition of the patient. The case was performed at the Central Medical College Hospital, Comilla utilizing the existing facilities. Fortunately the patient is doing well and leading a normal life after one and half years of operation.

(J Bangladesh Coll Phys Surg 2012; 30: 105-107)

complete excision of the mass ${ }^{5}$. This is a unique case of giant retroperitoneal schwannoma mimicking an adrenal tumour, encroaching upon renal hilum and posing threat to kidney. Application of all existing technological support and ground-breaking techniques of resection has evolved aiming to reduce blood loss and save the kidney.

\section{Case presentation and management}

Patient's History: A 55 years old lady presented with pain in the left side of upper abdomen and lump in the left hypochondriac and lumbar region for eleven months. Bladder and bowel habit of the patient was normal. The patient was mildly anaemic having below average nutritional status. Hemoglobin level was $9 \mathrm{gm} / \mathrm{dl}$ and other biochemical parameters were normal.

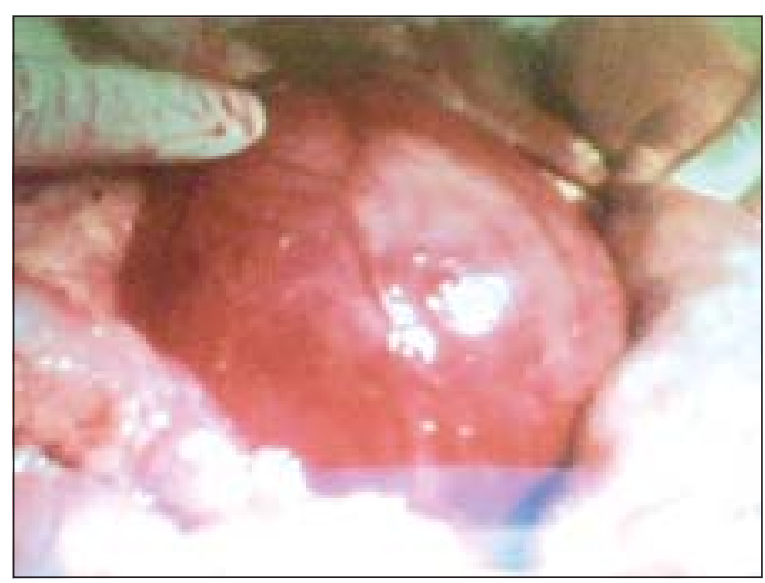

Fig.-1: Bigger lump with angry looking vessels on the surface of the lump 
Ultrasonography of whole abdomen revealed two big mixed echoic lump in left subcostal and lumbar region, the bigger one was compressing left renal hilum without any hydronephrosis. USG guided FNAC was inconclusive. Other site of abdomen was normal. CT scan was not possible due to poor financial condition of the patient. Anaesthetic fitness of the patient was within the normal limit. Five units of blood were arranged and two units were transfused preoperatively.

Surgical procedure: Under GA, the abdomen was explored through long midline incision, after packing of the small intestine into right side of the abdomen the bigger lump was exposed. Prominent blood vessels were observed on the surface of the lump (Fig. 1). Entrance into the retroperitoneal space was made after stripping off the peritoneum. Finger dissection was used to separate the large vessels from the lump and divided, ligated between the artery forceps. During separation of the lump from the posterior aspect, it was found tightly adherent to the left renal hilum.

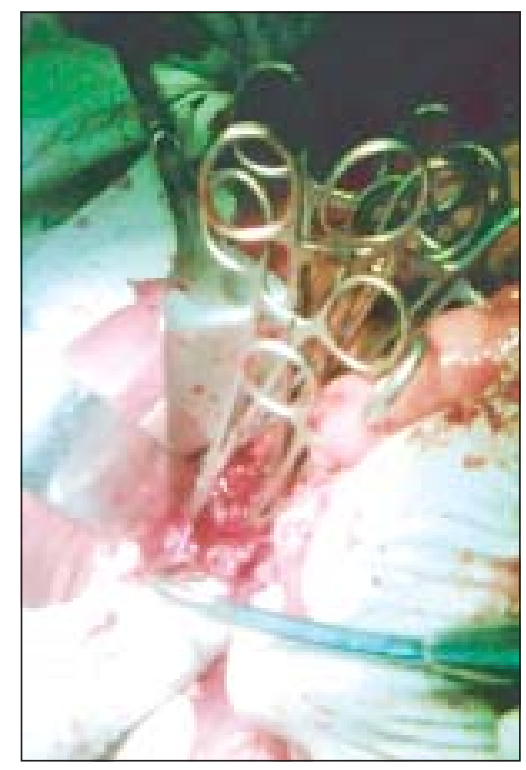

Fig. 2 Application of series of artery forceps

The renal pedicle was badly teared which the bigger lump $(11 / 10 \mathrm{~cm})$ was separated (Fig. 4). The wound rapidly filled with enormous amount of blood.

Suction and multiple hot mops were used to stop the bleeding. After removal of pack, there was serious bleeding. A series of artery forceps were used to stop the bleeding (Fig. 2).
After clearing of the operative field, the renal pedicle was ligated (Fig. 3). Due to avulsion of the kidney, it was removed (Fig. 4). Another small lump (7/6 cm) was removed successfully from the left subcostal region without further damage (Fig. 4). Wound was closed in layers with a drain kept in situ after securing every bleeding points. Total duration of operation was about two hours. Two units of blood were transfused peroperatively and one unit postoperatively. Condition of the patient remained stable during operation. In post operative period the patient remail well and recovered uneventfully. Histopathological section of two tumours revealed benign schwannoma.

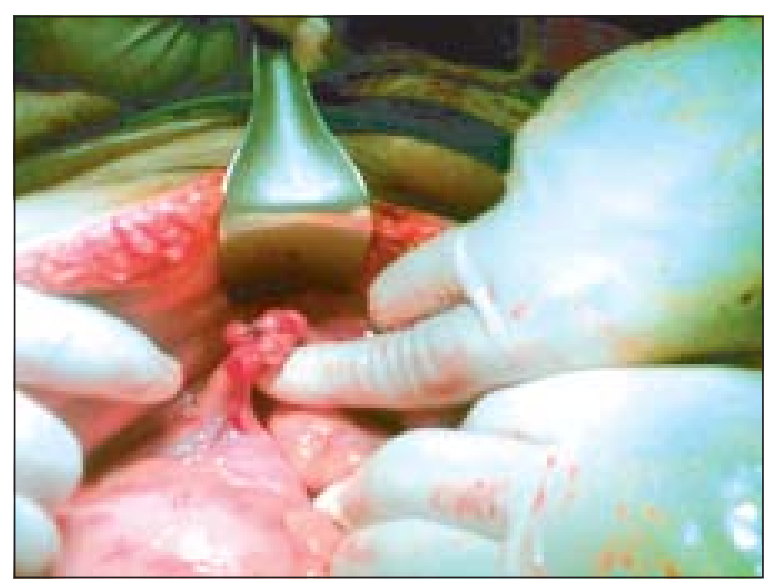

Fig.-3: Ligation of renal pedicle

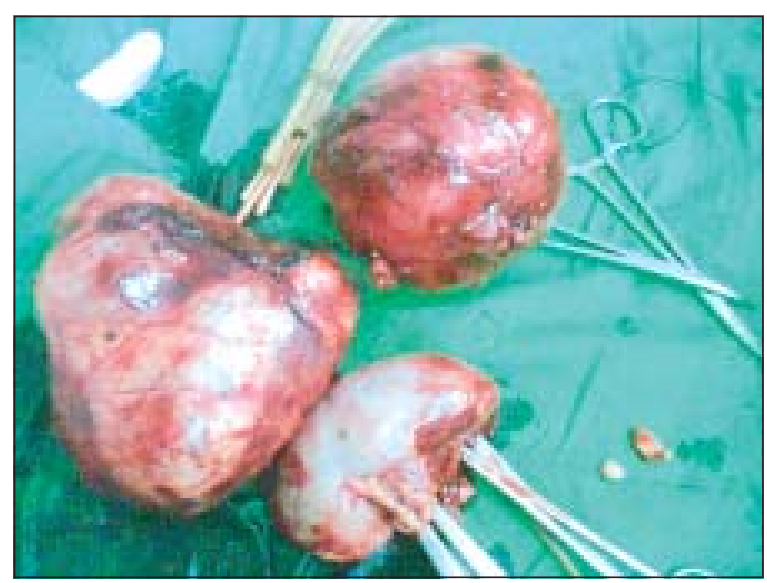

Fig.-4: Two removed lump with left kidney

\section{Discussion:}

Retroperitoneal schwannoma is a very rare tumour ${ }^{2,3}$. Preoperative diagnosis is very difficult despite modern equipped facilities ${ }^{6}$. Retroperitoneal tumours usually 
present without gastrointestinal or urological manifestations. Ultrasonography provided good clue to detect the origin of tumours and condition of the ipsilateral kidney. Fine-needle aspiration cytology was not helpful. CT scan was not done due to financial constrains. Accurate diagnosis is absolutely based on immunohistochemistry ${ }^{3}$.

Complete excision of the tumour is the only hope of cure $^{5}$. Adequate preoperative evaluation is mandatory to reduce operative morbidity. Long midline incision offers adequate exposure to almost every region of the abdominal cavity and retroperitoneum ${ }^{7}$. It is unsurpassed when speed is of the essence ${ }^{7}$.

Laparoscopic resection is an alternative choice ${ }^{8}$, but supervised training and support should be ensured. In our case, standard resection of the tumours were completed. Preservation of the left kidney was not possible. Facilities of vascular anastomotic technique might have save the kidney ${ }^{9}$.

Survival rate depends upon whether tumour is benign or malignant. Complete excision can cure benign case, survival rate of malignant schwannoma is $85 \%$ of 11years $( \pm 5)^{10}$. Recurrence is common in partial excision ${ }^{4}$.

\section{Conclusion:}

Retroperitoneal schwannoma is a locally aggressive tumour. Preoperative diagnosis is difficult with CT scan or FNAB. Surgical approach should focus on complete excision of the mass. Patient undergoing complete resection tend to do well without evidence of early recurrence.

\section{References:}

1. Cuschieri A, Steele C J R and Moossa R A. 2002. Disorders of the Retroperitoneum. Essential Surgical Practice. Arnold Publishers Ltd. $4^{\text {th }}$ edition. 2:165.

2. Behrend, Mathias, Kaaden, Stefan, Von W, Reinhard, Frericks and Bernd 2003. Benign retroperitoneal schwannoma mimicking an adrenal mass. Surgical endoscopy, laparoscopy and percutaneous technique. 13(2):133-138.

3. Kumar S, Singh K, Achara N, Radotra B D, Mandal K A and Kishore K V A. 2006. Renal preservationin a giant retroperitoneal schwannoma mimicking an adrenal mass. The Internet Journal of Urology. 6:1.

4. Qiangli, Chunatao G, Johanthan T, Juzi and Xishan H. 2007. Analysis of 82 cases of retroperitoneal schwannoma. ANZ Journal of Surgery. 77(4): 237-240.

5. Nah Y W, Suh J H, Choi D H, Ko B K, Nam C W, Kim G Y, Im Y C, and Cho H R. 2005. Benign retroperitoneal schwannoma: surgical consideration. Hepatogastroenterology. 52(66):1681-1684.

6. Daneshmand S, Youssefzadeh D, Chamie K, Boswell W, Wu N, Stein J P, Boyd S and Skinner D G 2003. Benign retroperitoneal schwannoma: a case series and review of the literature. Urology. 62(6):993-997.

7. Burt M B, Tavakkolizadeh A, Ferzoco J S. 2007. Incisions, closures and management of abdominal wound. Maingot's abdominal operations. Mcgraw - Hill Companies. $11^{\text {th }}$ edition. 4:73.

8. Yoshino T and Yoneda K. 2008. Laparoscopic Resection of a Retroperitoneal Ancient Schwannoma: A Case Report and Review of the Literature. International Journal of Cancer Research and Treatment. 28(5B):2889-2891.

9. Andrew C, Novick. 1996. Renal arterial grafts and renal bench surgery. Text Book of Operative Urology. W. B. Saunders Company. 36(2):311.

10. Qiang L and Chuntao G A O. 2006. Clinical Analysis of 81 Cases of Benign Retroperitoneal Schwannoma. The ChineseGerman Journal of Clinical Oncology. 5(1):28-30. 